\title{
Comparison of Starting Current Characteristics for Three-Phase Induction Motor Due to Phase-control Soft Starter and Asynchronous PWM AC Chopper
}

\author{
Veera Thanyaphirak*, Vijit Kinnares* and Anantawat Kunakorn*
}

\begin{abstract}
This paper presents the comparison of starting current characteristics of a three-phase induction motor fed by two types of soft starters. The first soft starter under investigation is a conventional AC voltage controller on the basis of a phase-control technique. The other is the proposed asynchronous PWM AC chopper which is developed from the conventional synchronous PWM AC chopper. In this paper, the proposed asynchronous PWM AC chopper control scheme is developed by generating only two asynchronous PWM signals for a three-phase main power circuit (6 switching devices) from a single voltage control signal which is compared with a single sawtooth carrier signal. By this approach, the PWM signals are independent and easy to implement since the PWM signals do not need to be synchronized with a three-phase voltage source. Details of both soft starters are discussed. The experimental and simulation results of the starting currents are shown. It is found that the asynchronous PWM AC chopper efficiently works as a suitable soft starter for the threephase induction motor due to that the starting currents are reduced and are sinusoidal with less harmonic contents, when being compared with the starting current waveforms using the conventional phase-control starting technique. Also the proposed soft starter offers low starting electromagnetic torque pulsation.
\end{abstract}

Keywords: Soft starter control, Asynchronous PWM, AC chopper, Induction motor

\section{Introduction}

High starting current of a three-phase induction motor (TPIM) is a significant problem in an industrial power system due to that the starting current is about to 5-7 times the rated motor current with a Direct On-Line (DOL) starting method. As a consequence it causes supply voltage dips which can adversely affect to other equipment connected to the power grid. To control the magnitude of the motor starting current, there are several soft start techniques which are used commercially. A soft starter with a phase-control technique is a popular technique because of circuit simplicity and convenient implementation [1-4]. The principle of the phase-control technique is based on varying the firing angle of two electronic switching devices (usually, Silicon Control Rectifier, SCR) so that the motor voltage waveforms can be adjusted $[2,3]$. However, the significant disadvantages of this soft starter are effects on the output voltage and current waveforms in terms of harmonic contents with high distortion and low harmonic orders $[2,3]$ resulting in derating of the induction motor.

\footnotetext{
$\dagger$ Corresponding Author: Dept. of Electrical Engineering, Faculty of Engineering, King Mongkut's Institute of Technology Ladkrabang, Thailand. (veerarmuti@gmail.com)

* Dept. of Electrical Engineering, Faculty of Engineering, King Mongkut's Institute of Technology Ladkrabang, Thailand. (\{kkwijit, kkananta\}@kmitl.ac.th)

Received: July 29, 2016; Accepted: December 19, 2016
}

To overcome waveform distortion issue of the phasecontrol starter, the active power filter can be employed for improving the power quality from the phase-control technique with the additional cost in the system $[5,6]$. There are alternatives in controlling the starting current of the motor. A PWM AC chopper is a suitable candidate technique since this technique offers less harmonic contents in the motor voltages and currents when being compared with the harmonic contents from the conventional phasecontrol technique [7-10].

In this paper, the comparison of starting current of a TPIM with a conventional phase-control soft starter and with the proposed asynchronous PWM AC chopper technique is detailed. It is noted that a soft start control scheme of the proposed asynchronous PWM AC chopper is developed so that the motor starting current can be reduced. The harmonic contents in supply voltages and currents are concerned when using the PWM AC chopper as a soft starter. The starting current of the TPIM using the proposed asynchronous PWM AC chopper soft-starter or "PWM Soft Starter (PWMSS)" is compared with the starting current of a "Direct On-line Control (DOC)" and the starting current of a "Conventional Phase-Control Soft-Starter (PCSS)". Various parameters such as starting voltage and ramp time are set in the scheme to observe the response of the control algorithm. Starting current and starting up time of the motor with PWMSS are considered from simulation results and experimental results. 


\section{Dynamic Model of Induction Motor}

The block diagram of a system in synchronously rotating reference frame with three-phase input voltage and threephase output current transformations is illustrated in Fig. 1 $[11,14]$. It consists of $3 \phi$ to $d-q$ transformation for voltage, $d-q$ to $3 \phi$ transformation for current and induction motor model block diagram. The $d-q$ axes dynamic equivalent circuits for the induction motor model are shown in Fig. 2(a) and (b) [11]. The $q$-axis and $d$-axis stator voltage and rotor voltage equations can be written as (1), (2), (3), and (4), respectively [11].

$$
\begin{aligned}
& v_{s q}=R_{s} i_{s q}+\frac{d}{d t} \psi_{s q}+\omega_{e} \psi_{s d} \\
& v_{s d}=R_{s} i_{s d}+\frac{d}{d t} \psi_{s d}-\omega_{e} \psi_{s q}
\end{aligned}
$$

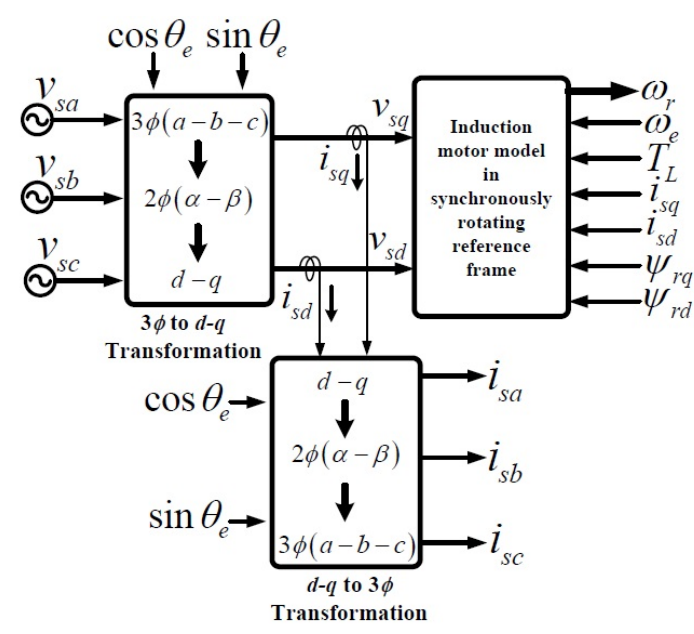

Fig. 1. Synchronously rotating reference frame machine model with input voltage and output current transformations

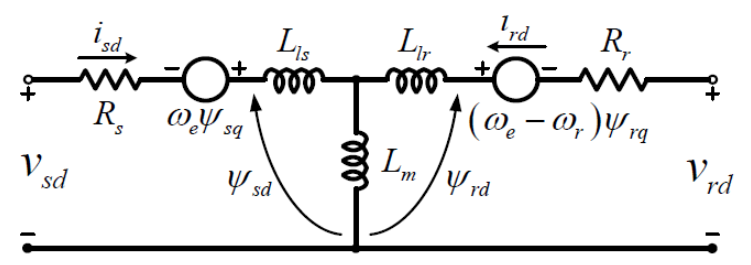

(a) $d$-axis

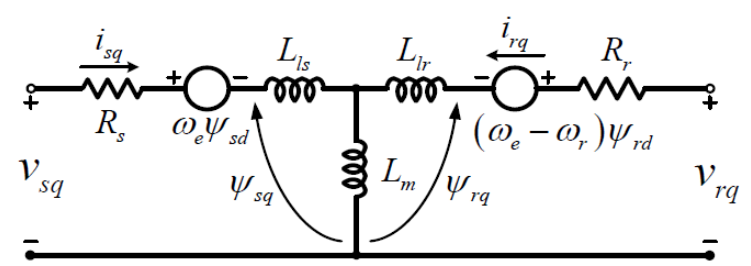

(b) $q$-axis

Fig. 2. Dynamic equivalent circuits of induction motor in $d-q$ axes synchronously rotating reference frame

$$
\begin{aligned}
& v_{r q}=R_{r} i_{r q}+\frac{d}{d t} \psi_{r q}+\left(\omega_{e}-\omega_{r}\right) \psi_{r d} \\
& v_{r d}=R_{r} i_{r d}+\frac{d}{d t} \psi_{r d}-\left(\omega_{e}-\omega_{r}\right) \psi_{r q}
\end{aligned}
$$

The flux linkage equations of the current term can be derived as (5)-(10).

$$
\begin{gathered}
\psi_{s q}=L_{l s} i_{s q}+L_{m}\left(i_{s q}+i_{r q}\right) \\
\psi_{r q}=L_{l r} i_{r q}+L_{m}\left(i_{s q}+i_{r q}\right) \\
\psi_{m q}=L_{m}\left(i_{s q}+i_{r q}\right) \\
\psi_{s d}=L_{l s} i_{s d}+L_{m}\left(i_{s d}+i_{r d}\right) \\
\psi_{r d}=L_{l r} i_{r d}+L_{m}\left(i_{s d}+i_{r d}\right) \\
\psi_{m d}=L_{m}\left(i_{s d}+i_{r d}\right)
\end{gathered}
$$

The flux linkage equations from (5)-(10) can be substituted to the stator and the rotor voltage equations (1)(4) .Then, the relationship between voltages and currents can be given as the matrix equation (11). Therefore, the stator currents and the rotor currents of both axes can be given by inverse matrix equation (11) and can be written as (12).

$\left[\begin{array}{c}v_{s q} \\ v_{s d} \\ v_{r q} \\ v_{r q}\end{array}\right]=\left[\begin{array}{cccc}R_{s}+S L_{s} & \omega_{e} L_{s} & S L_{m} & \omega_{e} L_{m} \\ -\omega_{e} L_{s} & R_{s}+S L_{s} & -\omega_{e} L_{m} & S L_{m} \\ S L_{m} & \left(\omega_{e}-\omega_{r}\right) L_{m} & R_{r}+S L_{r} & \left(\omega_{e}-\omega_{r}\right) L_{r} \\ -\left(\omega_{e}-\omega_{r}\right) L_{m} & S L_{m} & \left(\omega_{e}-\omega_{r}\right) L_{r} & R_{r}+S L_{r}\end{array}\right]\left[\begin{array}{c}i_{s q} \\ i_{s d} \\ i_{r q} \\ i_{r d}\end{array}\right]$

$\left[\begin{array}{c}i_{s q} \\ i_{s d} \\ i_{r q} \\ i_{r d}\end{array}\right]=\left[\begin{array}{cccc}R_{s}+S L_{s} & \omega_{e} L_{s} & S L_{m} & \omega_{e} L_{m} \\ -\omega_{e} L_{s} & R_{s}+S L_{s} & -\omega_{e} L_{m} & S L_{m} \\ S L_{m} & \left(\omega_{e}-\omega_{r}\right) L_{m} & R_{r}+S L_{r} & \left(\omega_{e}-\omega_{r}\right) L_{r} \\ -\left(\omega_{e}-\omega_{r}\right) L_{m} & S L_{m} & \left(\omega_{e}-\omega_{r}\right) L_{r} & R_{r}+S L_{r}\end{array}\right]^{-1}\left[\begin{array}{c}v_{s q} \\ v_{s d} \\ v_{r q} \\ v_{r q}\end{array}\right]$

where $S$ is the Laplace operator. For an induction motor, $v_{r q}=v_{r d}=0$. Knowing the inputs $v_{s q}, v_{s d}$ and $\omega_{e}$, the currents $i_{s q}, i_{s d}, i_{r q}$ and $i_{r d}$ can be solved from (12). The rotor speed $\left(\omega_{r}\right)$ in (11) cannot be treated as a constant during startup and transient conditions. The electromagnetic torque can be derived as (13).

$$
T_{e}=\left(\frac{3}{2}\right)\left(\frac{P}{2}\right) L_{m}\left(i_{s q} i_{r d}-i_{s d} i_{r q}\right)
$$

The stator currents in $d-q$ axes from (12) can be transformed to three-phase stator currents using the $d-q$ to the $3 \phi$ transformation block diagram as shown in Fig. 1 which can be derived as the matrix Eq. (14). 


$$
\left[\begin{array}{c}
i_{s a} \\
i_{s b} \\
i_{s c}
\end{array}\right]=\left[\begin{array}{cc}
\cos \theta_{e} & \sin \theta_{e} \\
\cos \left(\theta_{e}-\frac{2 \pi}{3}\right) & \sin \left(\theta_{e}-\frac{2 \pi}{3}\right) \\
\cos \left(\theta_{e}+\frac{2 \pi}{3}\right) & \sin \left(\theta_{e}+\frac{2 \pi}{3}\right)
\end{array}\right]\left[\begin{array}{c}
i_{s q} \\
i_{s d}
\end{array}\right]
$$

where $\theta_{e}$ is the angle of angular speed in synchronously rotating reference frame. When considering the dynamic model in the synchronously rotating frame, for a given motor, stator current depends on rotor speed and stator voltage. During startup, high starting current can be reduced with reduced stator voltage. If three-phase motor voltage waveforms are non-sinusoidal, stator currents are affected. The motor dynamic model in the synchronously rotating frame is performed on Matlab/Simulink for digital simulation. In this paper, the simulation results in terms of starting current and electromagnetic torque will be compared with the experimental results for all techniques.

\section{Conventional Phase-Control Soft Starter}

In this section, a phase-control technique which is used as a soft starter for the TPIM is briefly introduced. The PCSS is considered as the control and variation of input voltages which are supplied to the motor. The main power circuit of the PCSS is illustrated in Fig. 3. In this technique, three-phase soft starter control signals are generated so that the variation of voltages which are applied to the motor can be achieved. It is noted that the control signals must be synchronized with the three-phase voltages source, and depend on a firing angle $(\alpha)$. A sample waveform set at firing angle of 30 degrees ( $\alpha=30^{\circ}$ ) of three-phase back-toback-connected thyristors is illustrated in Fig. 4.

When the $\alpha$ value is varied from $0^{0}$ to $150^{\circ}$, the rms value of the output voltage ( $\left.V_{o, r m s}\right)$ supplied to the TPIM is changed and can be derived as follows [12].

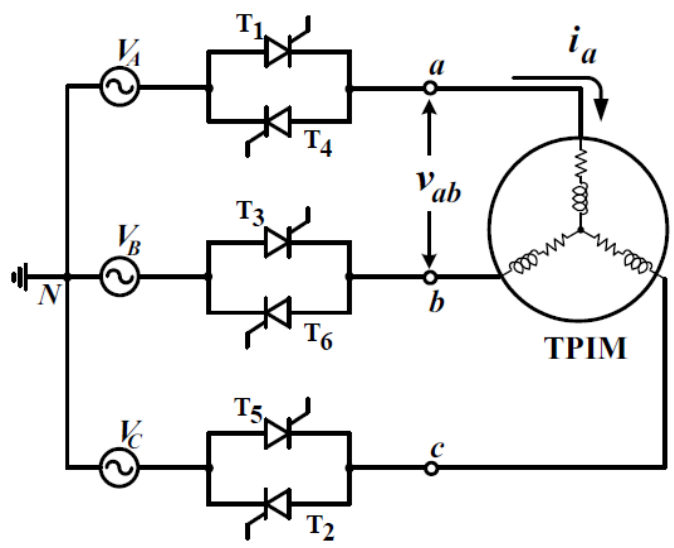

Fig. 3. Power circuit configuration of PCSS
For $0^{0} \leq \alpha<60^{\circ}$ :

$$
V_{o, r m s}=\sqrt{6} V_{s} \sqrt{\frac{1}{\pi}\left(\frac{\pi}{6}-\frac{\alpha}{4}+\frac{\sin 2 \alpha}{8}\right)}
$$

For $60^{\circ} \leq \alpha<90^{\circ}$ :

$$
V_{o, r m s}=\sqrt{6} V_{s} \sqrt{\frac{1}{\pi}\left(\frac{\pi}{12}+\frac{3 \sin 2 \alpha}{16}+\frac{\sqrt{3} \cos 2 \alpha}{16}\right)}
$$

For $90^{\circ} \leq \alpha<150^{\circ}$ :

$$
V_{o, r m s}=\sqrt{6} V_{s} \sqrt{\frac{1}{\pi}\left(\frac{5 \pi}{24}-\frac{\alpha}{4}+\frac{\sin 2 \alpha}{16}+\frac{\sqrt{3} \cos 2 \alpha}{16}\right)}
$$

The sample line voltage and phase current waveforms for PCSS are shown in Fig. 5(a) and (b), respectively. Both waveforms are non-sinusoidal. Also the motor current is discontinuous resulting in electromagnetic torque pulsation.

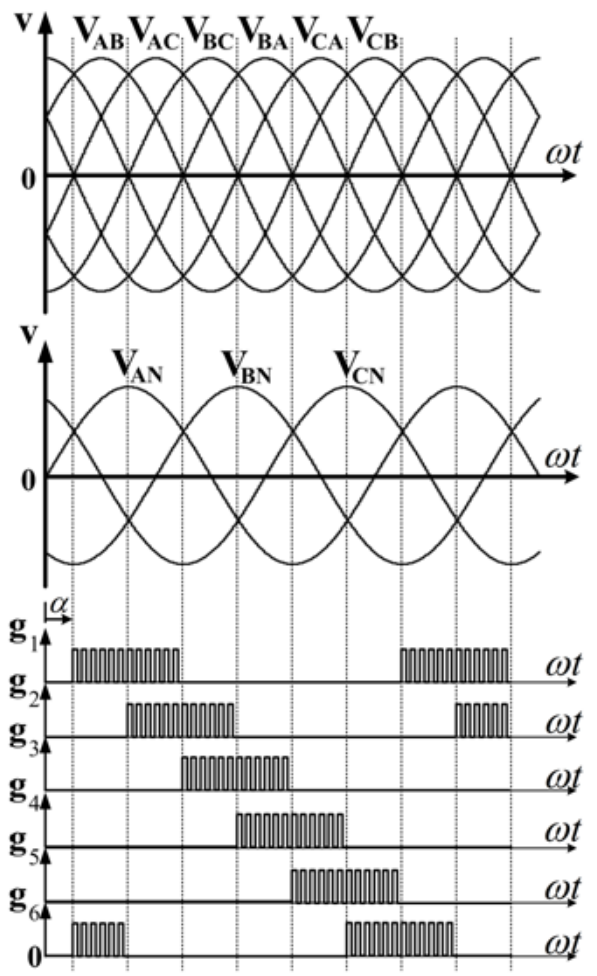

Fig. 4. Gate signals synchronized with the three-phase voltages source

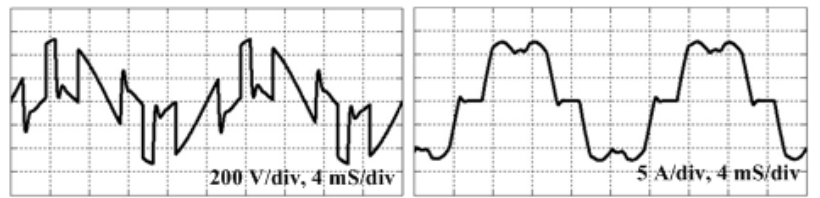

(a) $v_{a b}$

(b) $i_{a}$

Fig. 5. Line voltage and phase current waveforms for PCSS 


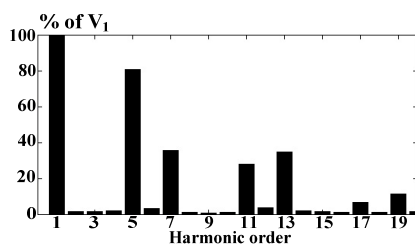

(a) Harmonic spectrum of $v_{a b}$

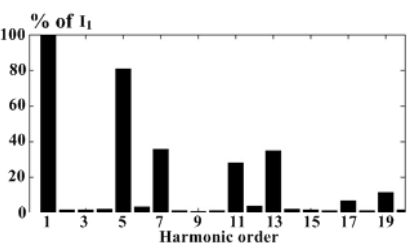

(b) Harmonic spectrum of $i_{a}$
Fig. 6. Line voltage and phase current spectra for PCSS

The corresponding peak harmonic contents normalized with the fundamental are shown in Fig. 6(a) and (b). The disadvantage of this technique is that low order harmonic contents which are $5^{\text {rd }}, 7^{\text {th }}, 11^{\text {th }}, 13^{\text {th }}$, etc. are present.

\section{Proposed Asynchronous PWM AC Chopper Configuration}

From the previous section, it showed that the voltage and current waveforms contain low order harmonic contents. In this section, a candidate approach as a soft starter for the TPIM is proposed. This approach is an application of a power converter circuit which is so-called a PWM AC chopper. The advantage of the PWM AC chopper is the elimination on harmonic contents in output voltage and current waveforms. The soft starter technique which is developed from the PWM AC Chopper is named as the PWM Soft Starter (PWMSS). The main power circuit of PWMSS is shown in Fig. 7(a).

As shown in Fig. 7(a), the power bidirectional switches $\left(\mathrm{SW}_{1}-\mathrm{SW}_{6}\right)$ are used for control of power flow between a source and the TPIM load. The PWM signals (Fig. 7(b)) are used for controlling all power bidirectional switches. A common asynchronous PWM signal is used for $\mathrm{SW}_{1}, \mathrm{SW}_{3}$ and $\mathrm{SW}_{5}$ whilst a common inverting asynchronous PWM signal is used for $\mathrm{SW}_{2}, \mathrm{SW}_{4}$ and $\mathrm{SW}_{6}$. This technique is very useful since the AC chopper does not require threephase voltage signals for generating PWM signals due to that the three-phase PWM signals do not need to be synchronized with a three-phase voltage source.

Fig. 8 illustrates per phase motor voltage waveform and PWM signal function $\left(f_{P W M}(t)\right)$ [13] which is the signal for $\mathrm{SW}_{1}, \mathrm{SW}_{3}$ and $\mathrm{SW}_{5}$. The chopping voltage can be calculated by multiplying between a supply voltage and a PWM signal function $\left(f_{P W M}(t)\right)$. The PWM signal function can be expressed in Fourier series as

$$
f_{P W M}(t)=a_{0}+\sum_{n=1}^{\infty}\left(a_{n} \cos n \omega_{c} t+b_{n} \sin n \omega_{c} t\right)
$$

where $a_{0}$ is the DC component, $a_{n}$ and $b_{n}$ are the Fourier components, $n$ is the harmonic order and $\omega_{c}$ is the angular carrier frequency. $a_{0}, a_{n}$ and $b_{n}$ can be derived as (19)(22) [13].

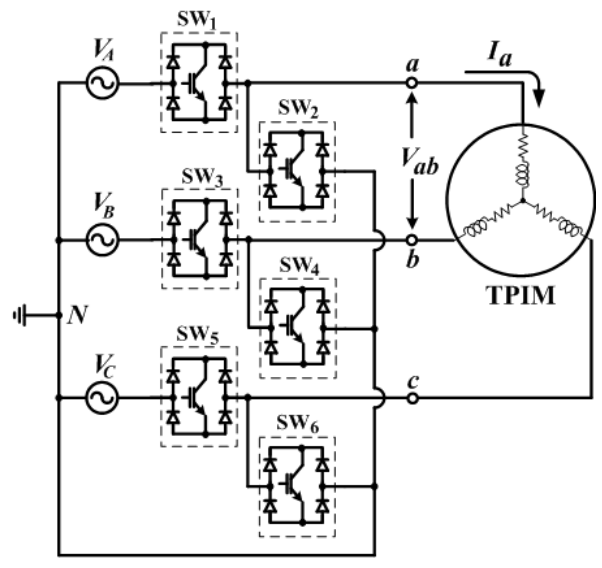

(a) Power circuit configuration

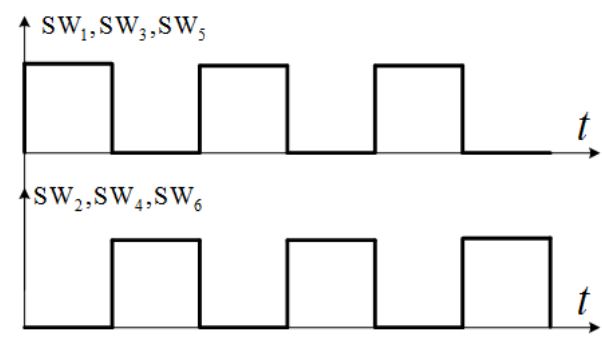

(b) PWM signals for controlling $\mathrm{SW}_{1}-\mathrm{SW}_{6}$.

Fig. 7. Power circuit and PWM signals for the proposed PWMSS

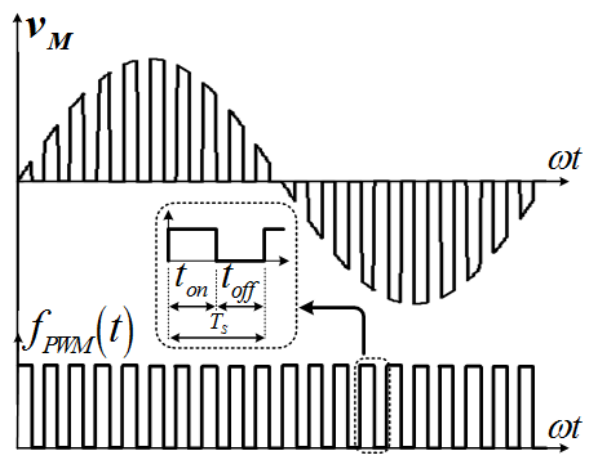

Fig. 8. Motor voltage waveform and PWM signal function

$$
\begin{gathered}
a_{0}=\frac{t_{\text {on }}}{T_{S}}=\frac{t_{\text {on }}}{t_{\text {on }}+t_{\text {off }}}=\frac{\hat{V}_{\text {cont }}}{\hat{V}_{\text {tri }}}=D \\
a_{n}=\frac{1}{n \pi} \sin (2 n \pi D) \\
b_{n}=-\frac{1}{n \pi}[1+\cos (2 n \pi D)] \\
c_{n}=\sqrt{\left(a_{n}^{2}+b_{n}^{2}\right)}
\end{gathered}
$$

where $t_{\text {on }}$ is the on-time period, $t_{\text {off }}$ is the off-time period, $T_{s}$ is the switching time, $\hat{V}_{\text {cont }}$ is the peak value of the 
control voltage, $\hat{V}_{t r i}$ is the peak of the carrier signal and $D$ is the duty ratio which is a ratio of the peak control voltage to the peak value of the sawtooth carrier signal. Therefore, the per phase chopping voltage supplied to the motor can be expressed as

$$
v_{M}(t)=v_{S}(t) \cdot f_{P W M}(t)=V_{m} \sin \omega t \cdot f_{P W M}(t)
$$

Substituting $f_{P W M}(t)$ from (18) into (23) yields

$$
\begin{gathered}
v_{M}(t)=a_{0} V_{m} \sin (\omega t)+\sum_{n=1}^{\infty}\left[a_{n} V_{m}\left(\cos n \omega_{c} t \cdot \sin \omega t\right)\right. \\
\left.+b_{n} V_{m}\left(\sin n \omega_{c} t \cdot \sin \omega t\right)\right]
\end{gathered}
$$

The chopping voltage consists of the fundamental component and the high frequency harmonic components. Therefore, when those are filtered, the fundamental phase voltage of the motor can be expressed as (25) which is linearly proportional to the $D$ value[13].

$$
v_{M_{1}}=a_{0} V_{m} \sin \omega t=D \cdot V_{m} \sin \omega t
$$

In the control scheme, the proposed PWMSS uses a comparison between a voltage signal and a carrier signal for generating PWM signals. In order to use the threephase PWM AC chopper for a soft starter control with the motor, the motor phase voltage can be varied by controlling on-time and off-time of bidirectional $\mathrm{SW}_{1}-$ $\mathrm{SW}_{6}$ thus varying the $D$ value of the PWM signals. The bidirectional $\mathrm{SW}_{1}, \mathrm{SW}_{3}$ and $\mathrm{SW}_{5}$ are alternately operated with the bidirectional $\mathrm{SW}_{2}, \mathrm{SW}_{4}$ and $\mathrm{SW}_{6}$. The scheme for generating the asynchronous PWM signals is shown in Fig. 9.

In this paper, the concept for PWMSS is varying the motor phase voltage from the initial voltage to the rated voltage with a given ramp time resulting in linearly increase of the duty ratio $(D)$ with the time. The smooth change in the motor voltage is possible. Profiles of the voltage ramp can be shown in Fig. 10. In the initial condition, the $D$ value is set at the initial value ( $\%$ of rated voltage). Therefore, the initial voltage value supplied to the motor is low. As a consequence, the motor starting current is low too. Then the $D$ value is gradually linearly increased resulting in gradually increased motor starting voltage and current. Until the steady-state condition, the $D$ value is increased to the final value of $100 \%$. As a consequence the bidirectional $\mathrm{SW}_{1}, \mathrm{SW}_{3}$ and $\mathrm{SW}_{5}$ are operated at on state all times. Before the motor speed approaches the synchronous

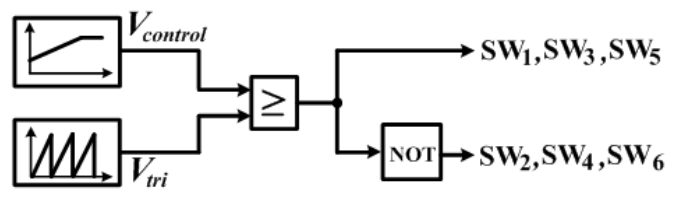

Fig. 9. Block diagram of asynchronous PWM generation speed, the motor current are suddenly decreased. Eventually the motor is operated at the rated voltage. According to a given voltage ramp from Fig. 10, PWM signals are varied as shown in Fig. 11. As can be seen, the pulse width of the PWM signal for $\mathrm{SW}_{1}, \mathrm{SW}_{3}$ and $\mathrm{SW}_{5}$ is increased from initial to final due to an increase in the $D$ value.

The sample line voltage waveform using the proposed asynchronous PWMSS is shown in Fig. 12(a), and it is found that the waveform is chopped in sinusoidal. This type of the waveform contains high order harmonic contents depending on a switching frequency of PWM signals. As a results the motor current waveform is nearly sinusoidal as shown in Fig. 12(b). When being compared with the output current waveform of the PCSS as in Fig. 5(b), it is obviously found that the proposed PWMSS gives the less distortion level in terms of output current waveforms. It is implied that the proposed PWMSS offers low electromagnetic torque pulsation for the motor. The

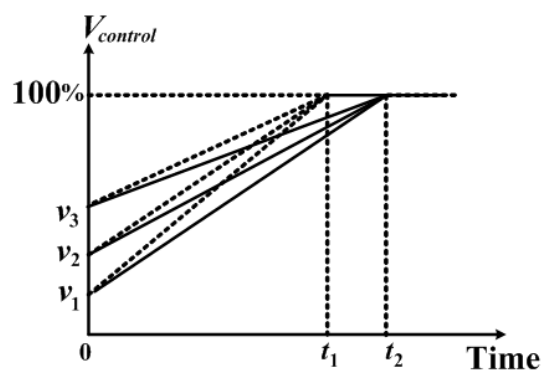

Fig. 10. Profile of voltage control ramp for case studies (case 3-8)

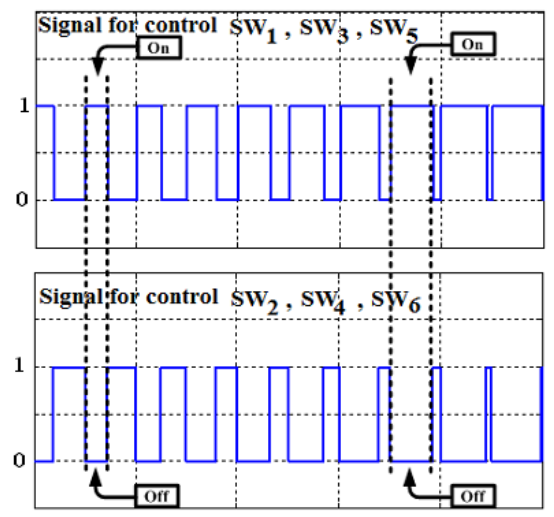

Fig. 11. Corresponding variation of PWM signals during start up

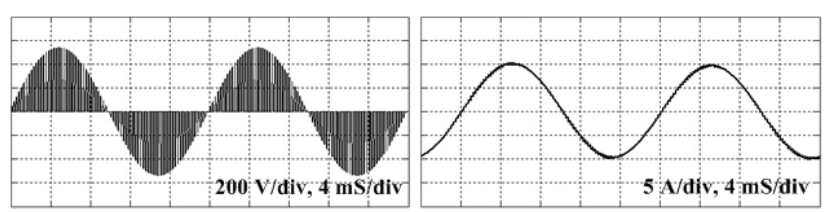

(a) $v_{a b}$

(b) $i_{a}$

Fig. 12. Line voltage and phase current waveforms for the proposed asynchronous PWMSS 

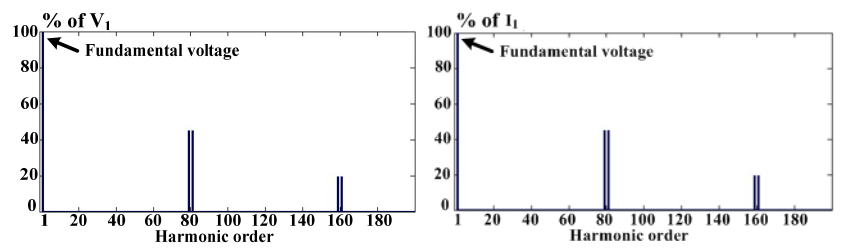

(a) Harmonic spectrum of $v_{a b}$

(b) Harmonic Spectrum of $i_{a}$

Fig. 13. Line voltage and phase current spectra for the proposed asynchronous PWMSS

corresponding line voltage and current spectra are shown in Fig. 13(a) and (b), respectively.

\section{Simulation and Experimental Results}

In previous sections, a concept of PCSS and PWMSS with their control scheme to reduce starting current of the TPIM was discussed. From simulation results, it has been found that the PWMSS has a capability in eliminating the harmonic contents in the motor current waveforms. To investigate the usefulness of these two techniques in controlling the starting currents of the TPIM, 8 case studies are investigated as follows:

Case 1: "Direct On-line Control (DOC)"

Case 2: "Conventional Phase-Control Soft-Starter (PCSS)"

Cases 3,4,5,6,7 and 8 : "PWM Soft Starter (PWMSS)" with different set up parameters as follows.

Case 3: The initial voltage is set at $20 \%\left(v_{1}\right)$ and the ramp time is set at $0.3 \mathrm{~s}\left(t_{1}\right)$.

Case 4: The initial voltage is set at $20 \%\left(v_{1}\right)$ and the ramp time is set at $0.5 \mathrm{~s}\left(t_{2}\right)$.

Case 5: The initial voltage is set at $30 \%\left(v_{2}\right)$ and the ramp time is set at $0.3 \mathrm{~s}\left(t_{1}\right)$.

Case 6: The initial voltage is set at $30 \%\left(v_{2}\right)$ and the ramp time is set at $0.5 \mathrm{~s}\left(t_{2}\right)$.

Case 7: The initial voltage is set at $40 \%\left(v_{3}\right)$ and the ramp time is set at $0.3 \mathrm{~s}\left(t_{1}\right)$.

Case 8: The initial voltage is set at $40 \%\left(v_{3}\right)$ and the ramp time is set at $0.5 \mathrm{~s}\left(t_{2}\right)$.

The parameters of the motor under investigation are obtained from conventional testing procedures such as a short circuit test, an open circuit test and an acceleration test. The motor details are shown in Table 1. The motor is used as a load for three different starting techniques which are DOC, PCSS and PWMSS. In all these 8 case studies, starting currents are measured by YOKOGAWA PZ4000 Power Analyzer. Computer simulations on MATLAB / Simulink in all case studies are also performed in order to study correctness of setting a testing bench.

\subsection{Case 1: DOC}

The first case study is to use DOC with the TPIM. The
Table 1. Parameters of the TPIM

\begin{tabular}{c|c|c|c|c|c}
\hline \hline Power & Voltage & Current & Frequency & Poles & Speed \\
\hline $2.2 \mathrm{~kW}$ & $220 / 380 \mathrm{~V}$ & $8.6 / 5 \mathrm{~A}$ & $50 \mathrm{~Hz}$ & 4 & $1,420 \mathrm{rpm}$ \\
\hline \hline$R_{s}$ & $R_{r}$ & $l_{l s}$ & $l_{l r}$ & $L_{m}$ & $J$ \\
\hline $3.67 \Omega$ & $2.50 \Omega$ & $12.23 \mathrm{mH}$ & $12.23 \mathrm{mH}$ & $232 \mathrm{mH}$ & $0.032 \mathrm{~kg} \cdot \mathrm{m}^{2}$ \\
\hline
\end{tabular}

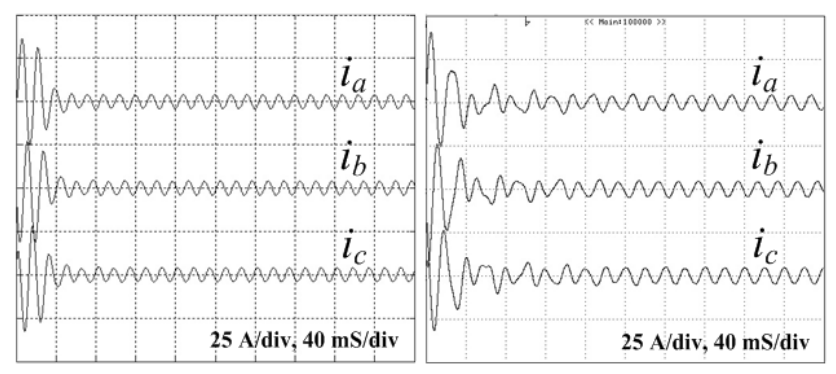

(a) Simulation

(b) Experimental

Fig. 14. Three-phase starting currents using DOC (case 1)

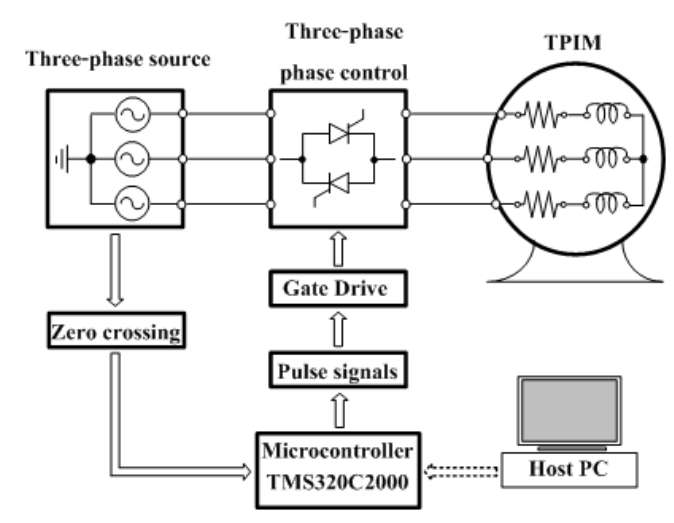

Fig. 15. Testing system of PCSS

motor parameters are applied in the simulation circuit on MATLAB/Simulink. The simulation and experimental results are shown in Fig. 14 (a) and (b), respectively. They are in good agreement which confirm the correctness of the motor parameters obtained from the tests in Table 1. Additionally, the amplitude of the motor starting currents is around $35 \mathrm{~A}$ (peak value), and the time to reach the steadystate condition is about $0.1 \mathrm{~s}$.

\subsection{Case 2: PCSS}

The second case is to use PCSS with the TPIM. There are several parameters in PCSS which should be addressed such as initial voltages and the ramp time. These parameters have an effect in the starting current of the motor. To include these parameters into the testing bench, a control algorithm is developed on the basis of a TMS320C200 microcontroller. To implement PCSS correctly, simulations have to be performed to adjust parameters of the PCSS. The test bench for the PCSS is set up as illustrated in Fig. 15. 


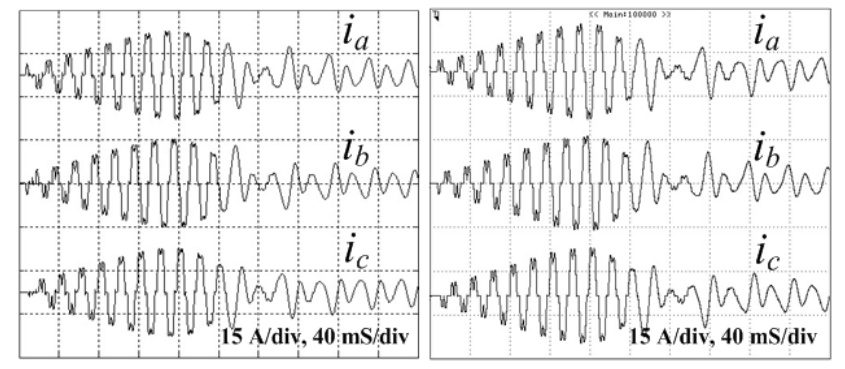

(a) Simulation

(b) Experimental

Fig. 16. Three-phase starting currents using PCSS (case 2)

As being mentioned, the starting voltage and the ramp time of PCSS can be varied, and can affect the starting current characteristics of the TPIM. For example, the starting voltage is set at $20 \%\left(v_{1}\right)$ of rated voltage and the ramp time is set at $0.5 \operatorname{Sec}\left(t_{2}\right)$. The firing angle $(\alpha)$ used in setting the initial voltage value is calculated from equation (17). The simulation results and the experimental results are shown in Fig. 16(a) and (b), respectively. The three-phase starting currents of the simulation results are in accordance with the experimental results. These results confirm the correctness of the motor parameters and the control scheme. Additionally, the amplitude of the motor starting currents using the PCSS is around 15 A (peak value), and the time to reach the steady-state condition is about $0.4 \mathrm{~s}$. Therefore, this technique can reduce the amplitude of the motor starting currents when being compared with the DOC.

\subsection{Cases 3,4,5,6,7 and 8 : proposed asynchronous PWMSS}

Other cases are to use the proposed PWMSS with the TPIM. The initial voltage and the ramp time are also parameters which can affect the starting current characteristics of the motor. The setting of these parameters are also taken into account when employing a TMS320C200 microcontroller as a control unit for a test bench.

The test bench for confirming the proposed PWMSS using the digital technique is constructed and illustrated in Fig. 17. The host pc is used for as a source to implement the control circuit with C-Language programming code with a MATLAB/Simulink toolbox. Then, the Code Composer Studio version 4 (CCS4) is used for complying the $\mathrm{C}$ code program to a microcontroller board with a TMS320C2000 slave digital signal processor. The microcontroller generates the asynchronous PWM signals which are sent to gate drive circuits to control the three-phase PWM chopper. A switching frequency of the PWMSS is set at $4 \mathrm{kHz}$. The three-phase bidirectional switches are constructed from IGBT discrete modules and fast-recovery power diodes. Fig. 18 shows the experimental setup.

The motor starting currents of the simulation results and the experimental results (case 3-8) using PWMSS are illustrated in Figs. 19-24, respectively. They are in good

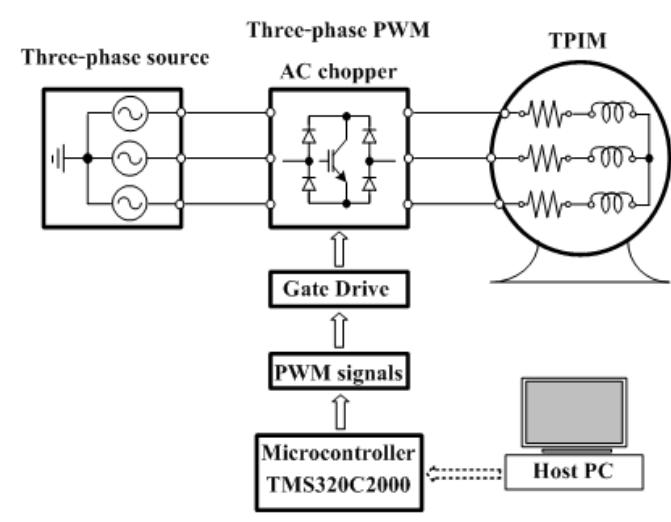

Fig. 17. Proposed system

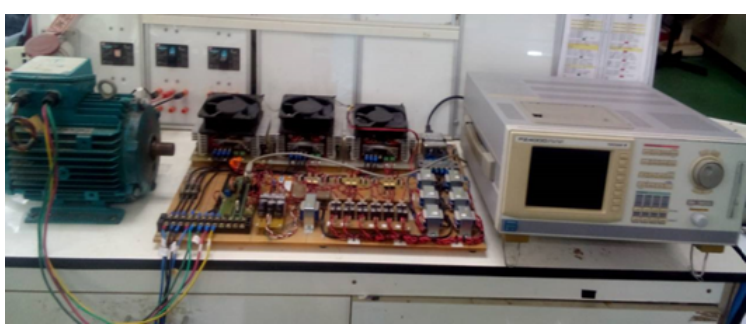

Fig. 18. Proposed hardware system and PZ4000 power analyzer

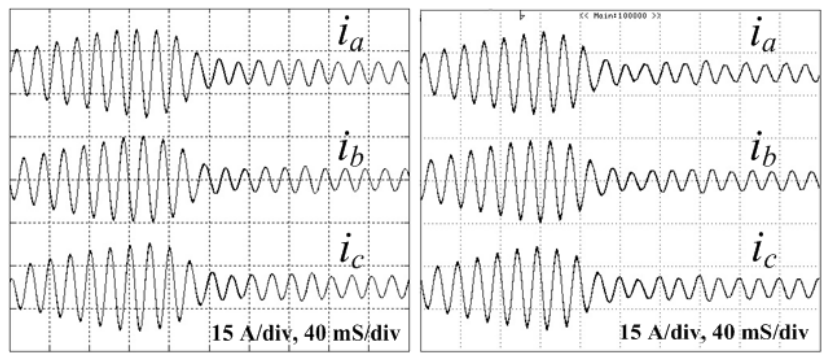

(a) Simulation

(b) Experimental

Fig. 19. Three-phase starting currents using PWMSS (case 3)

agreement which confirms the correctness of the proposed PWMSS.

The comparison between the results in case 3 and case 4 are shown in Figs. 19 and 20. It can be seen that the amplitudes of currents for case 4 are lower than those of case 3 since the ramp time for case 4 is longer than that for case 3 . While, the results of the motor starting currents in case 5 , case 6 , case 7 and case 8 show that the time to the steady-state condition of the motor currents is dependent on the ramp time which is set in the microcontroller. It is found that the amplitudes of the initial starting currents of case 3 are the same as those of case 4 because the starting voltage of the both cases are set equally. The initial starting currents from case 5 , case 6 , case 7 and case 8 are also equal. However, if the set value of the initial starting voltage is about $40 \%$ (case 7 and 8 ), the PWMSS is not functioned as a soft-starter because the amplitudes of the 


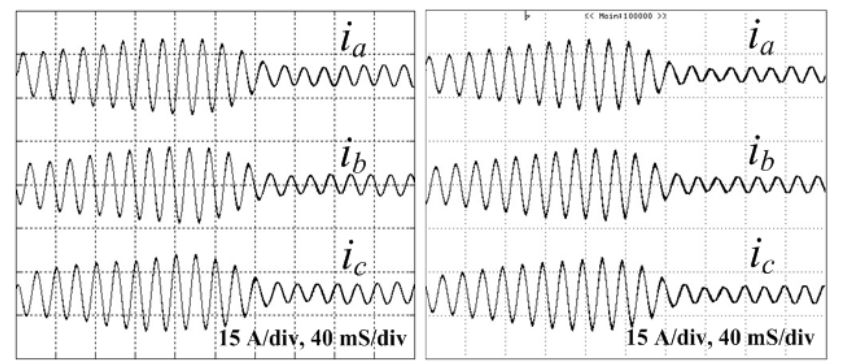

(a) Simulation

(b) Experimental

Fig. 20. Three-phase starting currents using PWMSS (case 4)

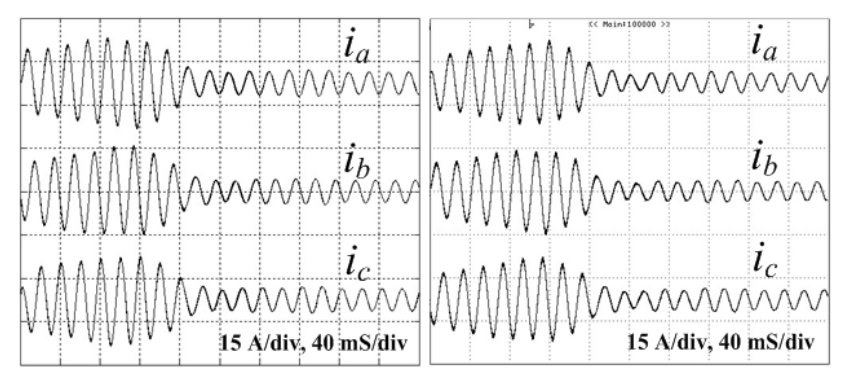

(a) Simulation

(b) Experimental

Fig. 21. Three-phase starting currents using PWMSS (case 5)

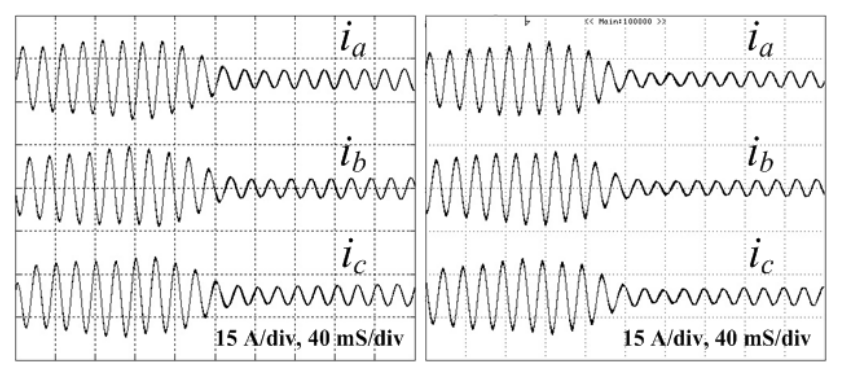

(a) Simulation

(b) Experimental

Fig. 22. Three-phase starting currents using PWMSS (case 6)

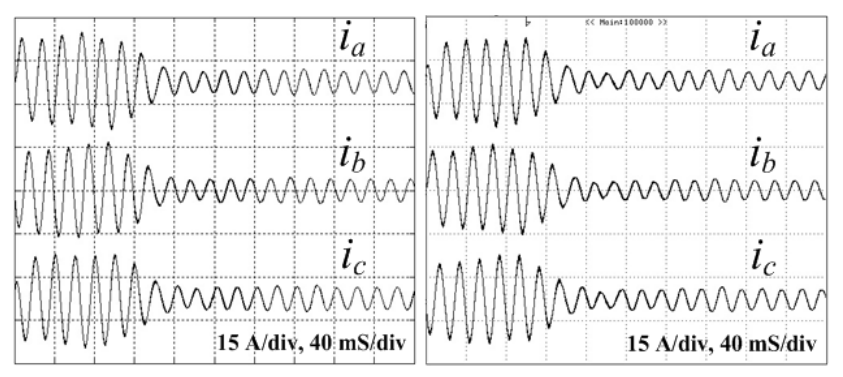

(a) Simulation

(b) Experimental

Fig. 23. Three-phase starting currents using PWMSS (case 7)

starting currents are not changed as shown in Figs. 23 and 24.

As shown in Figs. 19-24, the motor currents between the initial starting condition and the steady state condition are varied in PWMSS due to different starting voltages and ramp times. It is found that the starting current by case 4 is

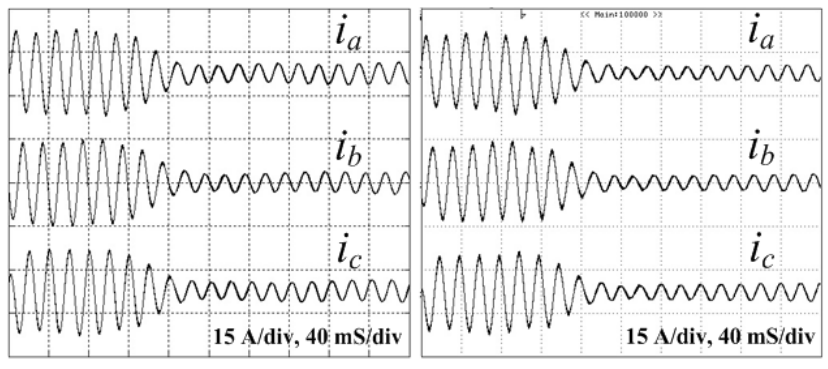

(a) Simulation

(b) Experimental

Fig. 24. Three-phase starting currents using PWMSS (case 8)

gradually increased until the steady state condition. Additionally, the maximum starting current of case 4 are lower than other cases. Therefore, the PWMSS with the starting voltage of $20 \%$ and the ramp time of $0.5 \mathrm{~s}$ is functioned properly and best suitable as a soft-starter for the motor under investigation.

\section{Simulation and Experimental Results of Total Harmonic Distortion in Starting Currents as Well as Electromagnetic Torque}

The starting currents using the PWMSS (case 4) are compared with those obtained from the PCSS (case 2) as shown in Figs. 26 and 21. The initial voltage and the ramp time of both PCSS and PWMSS are set equally. It is found that the motor starting current waveforms for the PWMSS are sinusoidal but there is distortion in starting current waveforms for the PCSS. This is according to the power quality issue of the PCSS as being discussed previously in section 2 of this paper. To further present the advantage of the proposed PWMSS in terms of less total harmonic distortion of the starting current waveforms, two additional cases are considered as follows :

Case 9 : PCSS

The initial voltage is set at $20 \%\left(v_{1}\right)$ and the ramp time is set at $1 \mathrm{~s}\left(t_{3}\right)$.

Case 10 : PWMSS

The initial voltage is set at $20 \%\left(v_{1}\right)$ and the ramp time is set at $1 \mathrm{~s}\left(t_{3}\right)$.

The starting currents for both cases are illustrated in Figs. 25 and 26, respectively. They are in good agreement. Obviously, as can be seen, current fluctuation occurs before the motor voltage reaches the rated value. The reason is that the motor voltage does not linearly varies with the firing angle. As a result the motor voltage does not smoothly vary during start up. In order to assess the harmonic contents of the starting currents, the maximum starting current (phase A) of 1 cycle during the start up process are used for calculating a spectrum frequency of the current. Then, the fundamental phase current and the 


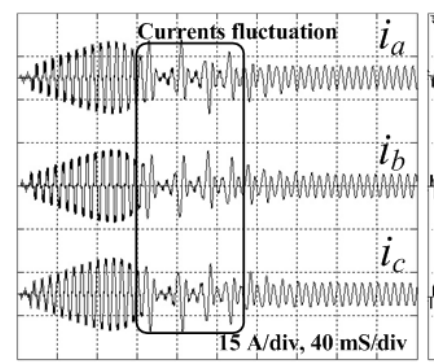

(a) Simulation

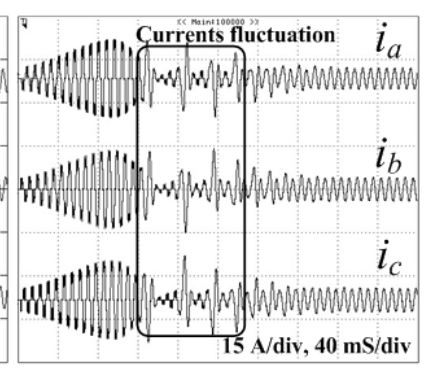

(b) Experimental
Fig. 25. Three-phase starting currents using PCSS (case 9)

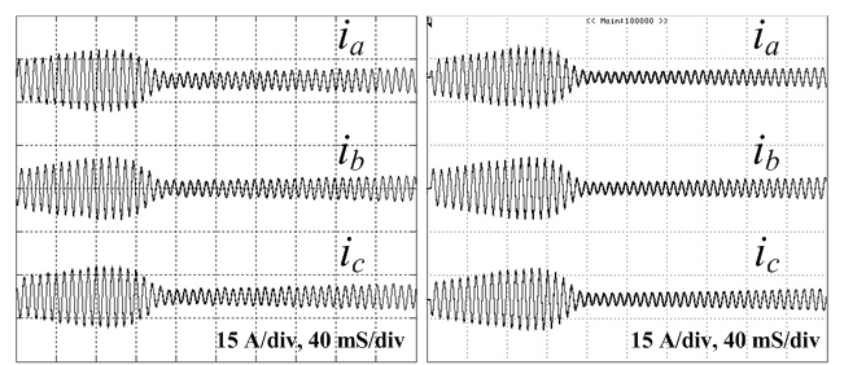

(a) Simulation

(b) Experimental

Fig. 26. Three-phase starting currents using PWMSS (case 10)

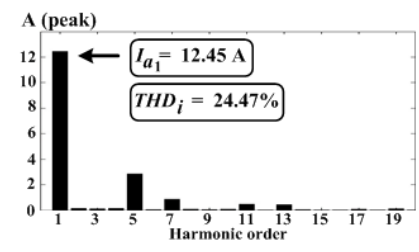

(a) Simulation

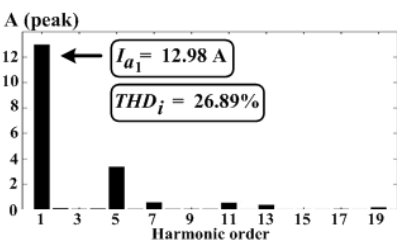

(b) Experimental
Fig. 27. Spectra of the motor phase current (phase A) using PCSS

Total Harmonic Distortion of the current (THDi) are extracted from the spectrum. The spectrum of the motor currents using the PCSS and the PWMSS are shown in Figs. 27 and 28, respectively. It is found that the harmonic components for both simulation and experimental results by PCSS consist of the fundamental current and low order harmonic such as $5^{\text {rd }}, 7^{\text {th }}, 11^{\text {th }}, 13^{\text {th }}$,etc. as shown in Fig. 27(a) and (b). The fundamental current magnitude and THDi for the simulation results are $12.45 \mathrm{~A}$ (peak) and $24.47 \%$ whilst those for the experimental results are $12.98 \mathrm{~A}$ (peak) and $26.89 \%$, respectively. It is noted that the harmonic components for simulation and experimental results by the PWMSS consist of the fundamental current only as shown in Fig. 28(a) and (b), respectively. The fundamental current magnitude and THDi for the simulation results are $10.33 \mathrm{~A}$ (peak), $0.46 \%$ whilst those for the experimental results are $10.34 \mathrm{~A}$ (peak), $0.95 \%$, respectively.

The another issue to prove that the proposed PWMSS is

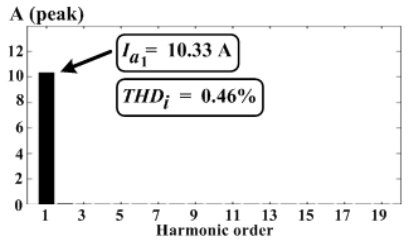

(a) Simulation

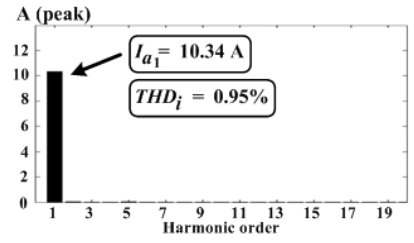

(b) Experimental
Fig. 28. Spectra of the motor phase current (phase A) using PWMSS

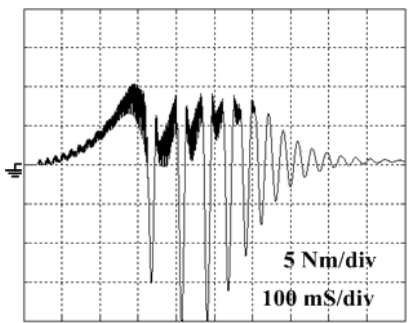

(a) Simulation

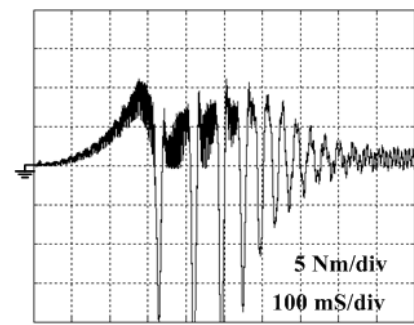

(b) Experimental
Fig. 29. Electromagnetic torque of the motor using PCSS

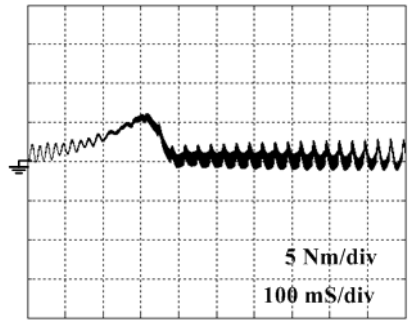

(a) Simulation

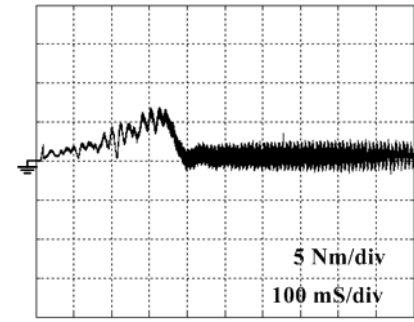

(b) Experimental
Fig. 30. Electromagnetic torque of the motor using PWMSS

suitable for soft starting is the comparison between starting electromagnetic torque for the PCSS and the proposed PWMSS as shown in Figs.29 and 30, respectively. Clearly, the proposed PWMSS gives less torque pulsation. For the PCSS, the large torque pulsation results from the starting current fluctuation (see Fig.25). Again the simulation and experimental results for the PCSS and the proposed PWMSS are in good agreement.

\section{Conclusion}

The comparison of starting currents of the TPIM due to DOC, PCSS and PWMSS has been discussed. The details of PCSS and PWMSS have been presented. For the PWMSS, a control scheme for a PWM AC chopper to operate as a soft-starter with an asynchronous operation in a PWM signal generating algorithm has been proposed and developed in this paper. Ten case studies have been investigated with the simulation on MATLAB/Simulink 
and with the experiments on test benches. It has been found that the PCSS and the PWMSS can be successfully employed to reduce the starting currents of the three-phase induction motor. Two parameters which are a starting voltage and the ramp time need to be properly set in softstarter control schemes in both techniques so that the PCSS and the PWMSS can function appropriately. The PWMSS has an advantage in terms of nearly sinusoidal waveforms in motor currents with less harmonic contents, and less electromagnetic torque pulsation when being compared with the motor currents obtained from the conventional PCSS technique.

\section{Acknowledgements}

The authors gratefully acknowledge the Ministry of Science and Technology, Thailand for the scholarship support.

\section{References}

[1] Gurkan Zenginobuz, Isik Cadirci, Muammer Ermis and Cuney Barlak, "Performance Optimization of Induction Motors During Voltage-Controlled Soft Starting", IEEE Trans. Energy Conversion, Vol. 19, pp. 278-288, Jun. 2004.

[2] Li Kai, Chen Xinglin and Wang Yan, "Analysis of Thyristor Controlled Induction Motors Based on VVCF," in Proceedings of the Eighth International Conference on Electrical Machines and Systems, vol.1, pp. 115-118, Sep. 2005.

[3] Hamdy A. Ashour and Rania A. Ibrahim, "Comparison Analysis of AC Voltage Controllers Based on Experimental and Simulated Application Studies," in Proceedings of the 2006 International Conference on Computer Engineering and Systems, vol. 1, pp. 79-84, Nov. 2006.

[4] Li Shue and Fu Chao, "Design and Simulation of Three-Phase AC Motor Soft-Start," in Proceedings of $3 r d$ International conference on Intelligent System Design and Engineering Applications, vol. 1, pp. 554-557, Jan. 2013.

[5] Bilal Saracoglu, Murat Kale and Engin Ozdemir, "A novel technique for Optimal Efficiency Control of Induction Motor Fed by PWM IGBT AC Chopper," in Proceedings of $35^{\text {th }}$ Annual 1EEE Power Electronics Specialists Conference, vol. 5, pp. 33533358, Jun. 2004.

[6] G. Bhuvaneswari, Charles S. and Manjula G. Nair, "Power Quality Studies on a Soft-Start for an Induction Motor, " in Proceedings of IEEE PES T\&D 2008 Conference, vol. 1, pp. 1-6, April. 2008.

[7] A. N. Arvindan, "Investigation for Power Quality in a PWM AC Controller feeding 3-phase, 3-wire Wye
Load," in Proceedings of IPEC 2010, vol. 1, pp. 648653, Oct. 2010.

[8] Charles S. and C. Vivekanandan, "Modelling and Power Quality Enhancement of Induction Motor with Soft Starter using Synchronous Reference Frame Theory," in Proceedings of International conference on Sustainable Energy and Intelligent Systems, vol. 1, pp. 47-51, Jul. 2011.

[9] Jose Thankachan and Saly George, "A Novel Switching Scheme for Three phase PWM AC Chopper Fed Induction Motor," in Proceedings of IEEE $5^{\text {th }}$ India International Conference on Power Electronics, vol. 1, pp. 1-4, Dec. 2012.

[10] V. Thanyaphirak, V. Kinnares and A. Kunakorn "Soft starting control scheme for three-phase induction motor fed by PWM AC chopper" in Proceedings of International Conference of Electrical Machines and Systems, Hangzhou, China, October 2014

[11] B. K. Bose, "Modern Power Electronics and AC Drives", Prentice-Hall, 2002.

[12] M. H. Rashid, "Power electronics: Circuits, Devices and Applications", Prentice-Hall, 2004.

[13] D. Yildirim and M. Bilgic, "PWM AC Chopper Control Single-Phase Induction Motor for variable Speed Fan Application", in Proceedings of $34^{\text {th }}$ Annual IEEE Industrial Electronics conference, Vol. 1, No. 1, pp. 1337-1342, Nov. 2008.

[14] Raúl Gregor, Guido Valenzano, Jorge Rodas, José Rodríguez-Piñeiro and Derlis Gregor, "Design and Implementation of an FPGA-based Real-time Simulator for a Dual Three-Phase Induction Motor Drive", Journal of Power Electronics, Vol. 16, No. 2, pp. 553-563, March 2016.

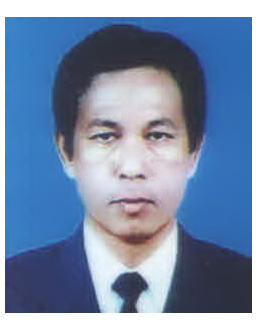

Veera Thanyaphirak $\mathrm{He}$ received B.Eng. in electrical engineering from Rajamangala Institute of Technology, Pathumthani, Thailand, in 1996, and M.Eng. in electrical engineering from King Mongkut's Institute of Technology Ladkrabang, Bangkok, Thailand, in 2004. Since 2011, he has worked for his D.Eng. in electrical engineering at King Mongkut's Institute of Technology Ladkrabang, Bangkok, Thailand. His research interests include energy conversion, electrical machines and electric drives.

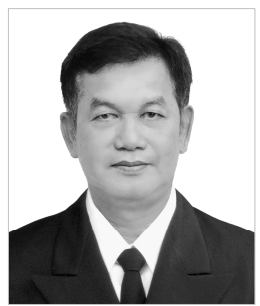

Vijit Kinnares He received B.Eng. (Hons.) and M.Eng. in electrical engineering from King Mongkut's Institute of Technology ladkrabang, Bangkok, Thailand, and Ph.D. in electrical engineering from the University of Nottingham, U.K., in 1997. He is an 
associate professor at King Mongkut's Institute of Technology Ladkrabang, Bangkok, Thailand. His current research interests include energy conversion, power electronics and electric drives.

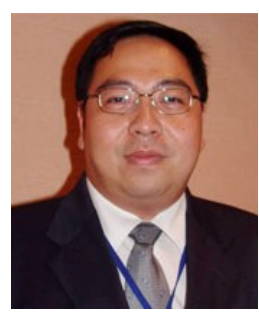

Anantawat Kunakorn $\mathrm{He}$ received B.Eng. (Hons.) in electrical engineeering from King Mongkut's Institute of Technology ladkrabang, Bangkok, Thailand, M.Sc. in electrical power engineering from the University of Manchester and Ph.D. in electrical engineering from Heriot-Watt University. He is an associate professor at King Mongkut's Institute of Technology Ladkrabang, Bangkok, Thailand. His current research interests include electrical machines and electromagnetic transients. 